\title{
INFLUÊNCIA DOS INDICADORES SOCIOECONÔMICOS NAS EXPORTAÇÕES: UM ESTUDO EM MUNICÍPIOS DA REGIÃO DAS MISSÕES E FRONTEIRA NOROESTE DO ESTADO DO RIO GRANDE DO SUL
}

\author{
INFLUENCE OF SOCIOECONOMIC INDICATORS ON EXPORTS: A STUDY IN \\ MUNICIPALITIES IN THE REGION OF THE MISSIONS AND THE NORTHWEST \\ BORDER OF THE STATE OF RIO GRANDE DO SUL
}

\section{Ronaldo Leão de Miranda ${ }^{1}$ \\ Glaucius André França ${ }^{2}$ \\ Nelson Hein ${ }^{3}$}

\section{Resumo}

O desenvolvimento de uma dada região passa pela exportação dos produtos locais e regionais. Desse modo, o presente artigo objetiva verificar a influência dos indicadores socioeconômicos nas exportações de produtos básicos e manufaturados dos municípios da região das Missões e Fronteira Noroeste do estado do Rio Grande do Sul. Metodologicamente, a pesquisa caracteriza-se como descritiva em relação a seu objetivo, aplicada quanto aos procedimentos, por meio do levantamento e a utilização de dados secundários, e quantitativa em relação à abordagem do problema, utilizando-se análise discriminante. Quanto aos resultados, observou-se que o indicador que possui maior influência nas exportações de modo geral é a população ocupada com 0,6679, na sequência, tem-se o IDEB com 0,5354, a urbanização de vias públicas com 0,4931 e o salário médio com 0,1267 , considerando os 45 municípios da região das Missões e Fronteira Noroeste como cenário de pesquisa. Com a análise discriminante, foi possível mensurar, por meio dos coeficientes padronizados, quais dos indicadores que possuem maior influência no caso de o município ser ou não exportador. Por fim, foi possível aceitar a hipótese de que existe uma relação de influência entre os indicadores socioeconômicos nas exportações tanto gerais quanto de produtos básicos e manufaturados.

Palavras-Chave: Indicadores Socioeconômicos. Exportações. Desenvolvimento Regional. Região das Missões do Rio Grande do Sul. Fronteira Noroeste do Rio Grande do Sul.

Manuscript first received/Recebido em: 10/10/2019 Manuscript accepted/Aprovado em: 29/11/2020

\footnotetext{
${ }^{1}$ Mestre em Desenvolvimento Regional. Doutorando em Ciências Contábeis e Administração pela Universidade Regional de Blumenau (FURB). Blumenau - SC - Brasil. E-mail: ronaldo leaomiranda@hotmail.com.

${ }^{2}$ Mestre em Ciências Contábeis e Atuariais. Professor da Universidade Estadual do Paraná (UNESPAR) e Doutorando em Ciências Contábeis e Administração pela Universidade Regional de Blumenau (FURB). Blumenau - SC - Brasil. E-mail: glaucius.franca@ outlook.com.

${ }^{3}$ Doutor em Engenharia de Produção. Professor do Programa de Pós-Graduação em Ciências Contábeis e Administração da Universidade Regional de Blumenau (FURB). Blumenau - SC - Brasil. E-mail: hein@ @urb.br.
}

\section{1}




\section{Abstract}

The development of a given region involves the export of local and regional products. Thus, the present article aims to verify the influence of socioeconomic indicators on the exports of basic products and manufactured goods from the municipalities of the Missions and Northwest Frontier region, of the state of Rio Grande do Sul. Methodologically, the research is characterized as descriptive in relation to its objective regarding the procedures can be considered as applied research from the secondary and quantitative data collection in relation to the approach of the problem, being analyzed through statistical techniques. Regarding the results, we have that the indicator that has the greatest influence on exports in general is the employed population of 0.6667, thus, we have the IDEB with 0.5354, the urbanization of public roads with 0, 4931 and the average salary of 0.1277, and the 45 municipalities in the Missions and Northwest Frontier region as a research scenario. These indicators had as function to measure through the standardized coefficients, which of these had greater influence of the municipality being or not exporter. Finally, it was possible to accept the hypothesis that there is a relationship of influence between the socioeconomic indicators in general exports as well as of basic and manufactured products.

Keywords: Socioeconomic Indicators. Exports. Regional development. Missions Region of Rio Grande do Sul. Northwest Border of Rio Grande do Sul.

\section{INTRODUÇÃO}

As regiões Missões e Fronteira Noroeste do Rio Grande do Sul são conhecidas por terem seu potencial de desenvolvimento econômico relacionado ao setor primário (básico), mas com uma parcela significativa no setor de serviços, comércio e manufaturados (indústria) (EVANGELISTA; RAMBO, 2007). Os reflexos deste processo de desenvolvimento ocorreram devido ao êxodo populacional, com a migração de indivíduos do campo para as cidades (ZUCATTO; FERASSO; EVANGELISTA, 2010). Desse modo, a teoria da base exportadora, de Douglas North, tem sido fundamental para explicar o dinamismo das regiões nas suas primeiras fases de desenvolvimento. Assim, parte-se do princípio de que o desenvolvimento de uma dada região passa pela exportação dos produtos locais e regionais, para outras regiões, ou até mesmo, para outros países, aumentando assim o faturamento das empresas e indústrias exportadoras (ZUCATTO; FERASSO; EVANGELISTA, 2010).

Neste contexto, a proposta deste estudo, em trabalhar estas duas regiões específicas do Estado do Rio Grande do Sul (Missões e Fronteira Noroeste) se justifica a luz de pesquisas que já foram realizadas nestas regiões, cuja temática é exportação (ZUCATTO; FERASSO; EVANGELISTA, 2010; OLIVEIRA et al., 2013). Dentre as pesquisas identificadas, está a de Zucatto et al. (2010) intitulada a importância das exportações para o desenvolvimento local da Fronteira Noroeste do Rio Grande do Sul e do extremo oeste de Santa Catarina. Neste caso, os autores investigaram as características das exportações das regiões, fronteira noroeste do Rio Grande do Sul e extremo oeste de Santa Catarina, e qual era sua importância para o desenvolvimento regional (ZUCATTO; FERASSO; EVANGELISTA, 2010). O estudo de Oliveira et al. (2013), reforçam a discussão, no sentido dos efeitos das exportações sob o nível do crescimento econômico de uma região, com base na teoria da base exportadora.

Em outros estudos, Ferreira \& Medeiros (2016) traçaram o perfil da base de exportação da região sul do Brasil, através da utilização dos dados de emprego formal nos anos de 2002, 2006 e 2010. O estudo de Lima et al. (2013) tratou da teoria da base de exportação e sua relação com o desempenho econômico 
do estado de Santa Catarina, e assim identificou quais são os setores chaves, no período pós 1990. Os autores Evangelista \& Rambo (2007) discutem os cenários e perspectivas para arranjos produtivos locais do agronegócio da Região Fronteira Noroeste do Rio Grande do Sul. Não tão recente, mas um trabalho fundamental, Dallabrida et al. (2007) discute estratégias de gestão do processo de desenvolvimento, realizando um diagnóstico e análise da região Fronteira Noroeste do Rio Grande do Sul.

Diante destes estudos anteriores, se reforça a ideia de que a teoria de base exportadora tenta explicar o desenvolvimento de uma determinada região baseada nas exportações (OLIVEIRA; NÓBREGA; MEDEIROS, 2013). No estudo de Both et al. (2020), fica evidenciado a importância e o crescimento das exportações na região missões, noroeste colonial, fronteira noroeste e celeiro do Rio Grande do Sul (RS). A análise demonstrou que as regiões analisadas, no período estudado, tiveram um importante incremento de exportações, da ordem de 326\%, ante um percentual de $338 \%$ a nível de país, e 288\% do Estado do Rio Grande do Sul (BOTH; THESING; TRENNEPOHL, 2020).No estudo de Silveira et al.(2019), foram confrontadas as variáveis população e renda dos países importadores com a exportação agropecuária do RS, e o principal resultado indicou que há uma relação positiva destas variáveis frente aos fluxos de comércio do setor agropecuário do estado do Rio Grande do Sul. Logo, o estudo citado, evidencia que as variáveis população e renda são legítimas, reforçando a abordagem proposta neste estudo no que tange a estas duas variáveis.

Assim sendo, este estudo se justifica teoricamente, com o intuito de contribuir para a literatura vigente, no sentido de evidenciar o quão importante são os indicadores socioeconômicos, quando se está analisando o potencial exportador de determinada região ou município, especialmente na região analisada. Contudo, do ponto de vista prático, tem o foco em elucidar se determinados indicadores (Salário Médio, Índice de Desenvolvimento da Educação Básica - IDEB, Urbanização de Vias Públicas e População Ocupada) influenciam no fato do município ser ou não exportador e qual o grau dessa influência. Já a justificativa para desenvolver este tipo de estudo, com estas variáveis, está na elucidação, se existe ou não, alguma influência dos indicadores socioeconômicos nas exportações de produtos básicos e manufaturados dos municípios da região das Missões e Fronteira Noroeste do estado do Rio Grande do Sul.

Partindo-se desse preceito, a questão norteadora desta pesquisa é: Os indicadores socioeconômicos influenciam nas exportações de produtos básicos e manufaturados dos municípios da região das Missões e Fronteira Noroeste do estado do Rio Grande do Sul? Assim, o presente artigo, objetiva verificar a influência dos indicadores socioeconômicos nas exportações de produtos básicos e manufaturados dos 45 municípios da região das missões e fronteira noroeste do estado do Rio Grande do Sul.

Este trabalho está dividido em cinco seções, sendo composto primeiramente por esta introdução e logo parte-se para a revisão da literatura. A terceira parte, diz respeito aos procedimentos metodológicos, em seguida tem-se a apresentação dos resultados e análises, e por fim, as considerações finais.

\section{REFERENCIAL TEÓRICO}

O referencial teórico deste estudo está dividido em cinco subseções: Desenvolvimento Regional e Local; Exportação e Desenvolvimento Regional; Teoria da Base Exportadora; Exportações no Rio Grande do Sul e por fim, discussões ligadas a Região Noroeste do Rio Grande do Sul.

\subsection{Desenvolvimento Regional e Local}

Não é possível pensar uma região desvinculada das questões que envolvem as influências nacional e internacionais. No que diz respeito ao desenvolvimento regional, em uma perspectiva 
econômica, apoia-se no pensamento de que as localidades dispõem de recursos e economias de escala que ainda não foram exploradas, tornando-se potencial de desenvolvimento do território brasileiro. No entanto, tratar da questão que envolve o conceito de desenvolvimento é associar com os adjetivos local, integrado e sustentável, que constroem (sic) o Desenvolvimento Local Integrado e Sustentável (DLIS), como é conhecido o processo no Brasil. Não é possível falar do desenvolvimento local sem referência a conceitos como pobreza e exclusão, participação e solidariedade, produção e competitividade, entre outros que se articulam e reforçam mutuamente ou se opõem frontalmente (FISCHER, 2004).

Segundo Fochezatto (2010), as teorias que sustentam as discussões sobre desenvolvimento regional não se restringem apenas as perspectivas microeconômicas, mas também aquelas focadas em abordagens macroeconômicas, cujo elemento central da análise são a demanda agregada e os seus potenciais efeitos multiplicadores sobre a produção via interligações setoriais (linkages setoriais). No mundo contemporâneo, as abordagens podem ser caracterizadas como sendo do tipo mesoeconômicas, cujo foco são a região e o seu potencial competitivo em um ambiente cada vez mais integrado com outras regiões e países. Ressalta-se North (1977), que ao estudar o desenvolvimento regional nos Estados Unidos, concluiu categoricamente que tal desenvolvimento se faz ideologicamente dentro de algumas fases, nesta ordem: economia de subsistência, industrialização modesta, sucessão de culturas agrícolas, industrialização forçada e especialização em atividades terciárias com produtos de exportação.

Vale ressaltar que o desenvolvimento regional não vincula-se apenas as questões que envolvem o espaço, a lucratividade, competitividade, mas também as dinâmicas dos processos endógenos e exógenos em uma rede de interinfluência, com outros vetores, além do capital financeiro, e diversos moduladores, como o capital social, a democracia, as dinâmicas territoriais, as organizações empresariais e as estratégias de gestão do desenvolvimento; acrescentam-se os processos de formação, as políticas governamentais e a cultura local (FRANZIN et al., 2015; SOTO, 2003). Porém, o mundo globalizado reforça a ideia da importância do desenvolvimento local, como predisposição necessária a constituição de identidades e diferenciação entre regiões, para que possam enfrentar o mercado competitivo.

A seguir, apresenta-se a discussão do desenvolvimento regional na perspectiva econômica, voltada aos fatores exógenos (NORTH, 1977).

\subsection{Exportação e Desenvolvimento Regional}

O mercado internacional é importante para o desenvolvimento das regiões, do Brasil, da agricultura e da indústria como um todo (VIEIRA FILHO; FISHLOW, 2017). Por outro lado, a introdução de inovações no contexto organizacional, possui forte efeito nos fluxos comerciais de um país com outro e aliada à estrutura produtiva de uma economia contribuem para o aumento da competitividade dos fluxos, gerando emprego e renda (BRAGA; MELO, 2017). A dinâmica do comércio internacional pode representar um elemento-chave sobre as condições de desenvolvimento de determinadas economias nacionais, principalmente no que tange a emprego e renda (FARIAS; FARIAS, 2018). Desse modo, uma região que recebe a influência do exterior pode aproveitar do comércio com este, principalmente, no que tange a questão de exportar, como uma ferramenta potente para o crescimento econômico, mas desde que tal atividade contribua para o desenvolvimento da região exportadora. 
Tem-se pensado como viável para o fortalecimento das micro e pequenas empresas, o consórcio de exportação, para promoção e facilitação de alianças, aproximando várias empresas, constituindo uma rede de relacionamento entre empresas do território e instituições locais (ZUCATTO, FERASSO; EVANGELISTA, 2010). Segundo Souza (1999), ao pensar em um modelo ideal de desenvolvimento deve-se considerar a combinação da expansão rápida das exportações juntamente com substituições seletivas de importações, oferecendo mudanças em suas tecnologias bem como diversificando uma rede de interdependências entre as atividades econômicas. $\mathrm{O}$ autor destaca que não se pode esquecer que existem várias vantagens de um modelo voltado ao crescimento das exportações, dentre elas:

$1^{\mathrm{a}}$ - As exportações podem complementar o mercado interno, com o intuito de desafogar os estoques não-vendidos, principalmente, quando houver capacidade ociosa, dada a demanda interna saturada;

$2^{\mathrm{a}}$ - O crescimento da produção devido as exportações favorecem a fomentação de economias de escala, diminuindo os custos médios, por conta da diluição dos custos fixos, e aumentando a margem de lucro, o que estimula os investimentos, fornecendo novos empregos no mercado interno pelos efeitos de multiplicação;

$3^{\mathrm{a}}$ - As exportações contribuem para ajudar na melhoria da eficiência produtiva interna, visto que a concorrência gerada pelos mercados externos gera a uma maior especialização e à preservação de elevados padrões de eficiência e competitividade;

$4^{\mathrm{a}}$ - O aumento das exportações facilita uma melhoria no aproveitamento dos recursos disponíveis, diminuindo a ociosidade produtiva da economia e aumentando o emprego dos recursos disponíveis, tais como terras, mão de obra, empresariado, capitais, dentre outros;

$5^{a}$ - As exportações contribuem significativamente para a criação de um processo de interdependência econômica bem como tecnológica com empresas do mercado interno, pois leva a ocorrer uma maior demanda de serviços e compras de insumos e bens de capitais produzidos internamente.

Apesar de todas as vantagens apresentadas acerca de um modelo de desenvolvimento de exportações, não se pode desconsiderar que toda atividade de exportação se desenvolve, também, com o apoio de diferentes serviços, apoiado em infraestrutura básica. Isso significa dizer que não é a atividade exportadora em si mesma que é responsável pelo desenvolvimento do país ou da região. Para melhor entendimento dessa questão, aborda-se a teoria de base econômica (teoria de base exportadora) que considera elementos que, com a diversificação econômica, expandem o nível de renda e emprego, tais como: construção civil e obras de infraestrutura; gastos de turistas; e transferências de renda de não residentes (SOUZA, 2009).

\subsection{Teoria da Base Exportadora}

A teoria de base foi defendida por Douglas North (1977), em seu artigo "Teoria da Localização e Crescimento Regional", sendo a primeira teoria da base de exportação que trata do crescimento regional a agregar a exportação como elemento chave para o crescimento de uma determinada região. Isso porque, essa teoria entende que as exportações exercem um efeito multiplicador sobre a economia. Além disso, essa teoria explica o dinamismo das regiões nas suas primeiras fases de desenvolvimento; no entanto, é em estágios mais avançados de desenvolvimento regional que tal teoria torna-se mais apropriada por engendrar, além das exportações, também o afluxo externo de

\section{5}


renda. Esta teoria analisa os efeitos geradores das atividades tanto básicas como as conhecidas como não básicas sobre a economia total, ou atividade total. Sendo as primeiras aquelas voltadas ao mercado externo, ou seja, exportação; enquanto as segundas destinadas ao abastecimento do mercado interno ou local (SOUZA, 2002).

A Teoria da Base Exportadora traz o fator exógeno (fora da região), aquele que promove o bemestar econômico de uma localidade pela produção de excedentes, isso quer dizer, maiores lucros, os quais fortalecem as pequenas e médias empresas que os originaram e, muitas vezes, podem dar origem a outros negócios e estimular uma variedade econômica ao nível local, até como forma de diversificar as possibilidades da economia prosperar (OLIVEIRA; FERASSO, 2018). Muitas das críticas à teoria da base de exportação têm se preocupado com os problemas de medir o tamanho do setor exportador ou básico e a razão entre os componentes básicos e não básicos da economia regional (THOMAS, 1964). Mesmo assim, atrelado as atividades exportadoras, a teoria da base de exportação chama a atenção para considerar na constituição da base econômica regional, variáveis como investimento autônomo interno, gastos do governo federal e entrada de capitais estrangeiros.

Outros autores em seus trabalhos também fazem uma crítica nessa mesma perspectiva da teoria de base no que diz respeito de que tal teoria não estuda outras variáveis que influenciam o crescimento de uma região, como, por exemplo, investimentos privados ou públicos que podem ter efeito maior e mais significativo sobre a renda de uma região do que simplesmente a variação das exportações (OLIVEIRA; NÓBREGA; MEDEIROS, 2012). Embora vários estudos tratem que a Base de Exportação é um fator importante para o crescimento das regiões, porém, é importante destacar que esse fator não é o único para que a região se desenvolva socioeconomicamente, importante lembrar a importância e a necessidade da diversificação setorial (LOBO, 2019). No entanto, apesar das críticas em relação a teoria de base, ainda assim, nesse estudo, entende-se que a base de exportação pode desempenhar um papel na determinação da renda regional, no curto prazo.

Neste contexto, o tópico seguinte aborda as exportações de modo geral do estado do Rio Grande do Sul.

\subsection{Exportações no Rio Grande do Sul - RS}

Segundo o atlas socioeconômico (2019), na última década, o Rio Grande do Sul foi influenciado pela entrada da China no mercado internacional, isso porque a demanda deste país por commodities agrícola aumentou relevantemente as exportações gaúchas de produtos primários (básicos), que se caracterizaram por apresentar baixo valor agregado e intensidade tecnológica baixa. Consta ainda no atlas que a soja é o principal produto na pauta das exportações gaúcha. Em 2017, a exportação de soja foi responsável por 26\% do total, somando 4,3 bilhões de US\$. Em menor valor tem-se o fumo, carnes de frango, suíno e outros resíduos da extração de óleo de soja. Integram a lista também produtos manufaturados, como os automóveis.

A principal via de transporte para exportação dos produtos gaúchos é a marítima e pelo porto de Rio Grande, chegando a um valor de 12 bilhões de US\$ por ano. Em segundo lugar está o transporte rodoviário com saída pelo município de São Borja e Uruguaiana via Ponte Internacional de Integração. Para melhor panorama da realidade gaúcha acerca das exportações no ano de 2019, apresenta-se o quadro 1 que traz informações sobre os principais produtos e principais destinos das exportações do Rio Grande do Sul. 
Quadro 1 - Produtos e destinos das exportações do RS no ano de 2019

\begin{tabular}{|c|c|c|c|}
\hline Produtos & $\begin{array}{l}\text { US\$ } 1000 \\
\text { FOB }\end{array}$ & $\%$ & $\begin{array}{l}\text { Principal } \\
\text { Destino }\end{array}$ \\
\hline Soja, mesmo triturada, exceto para semeadura & 4.634 .05 & 26.05 & China \\
\hline $\begin{array}{l}\text { Tabaco n/manufaturado, total ou parcialmente destalado, em } \\
\text { folhas secas em secador de ar quente do tipo Virgínia }\end{array}$ & 1.329 .293 & 7.48 & China \\
\hline $\begin{array}{l}\text { Automoveis com motor explosão, de cilindrada superior a } \\
1000 \mathrm{~cm}^{3} \text {. mas não superior } \mathrm{a} \mathrm{cm}^{3} \text {. }\end{array}$ & 642.569 & 1,47 & Argentina \\
\hline Bagaços e outros resíduos sólidos, da extração do óleo de soja & 605.799 & 1.18 & Eslovênia \\
\hline Carnes de galos / galinhas não cordadas em pedaços, congelada & 547.849 & 1.17 & Egito \\
\hline $\begin{array}{l}\text { Pedaços e miudezas, comestíveis de galos / galinhas, } \\
\text { congelados. }\end{array}$ & 543.469 & 1.17 & China \\
\hline Outras carnes de suínos congeladas & 433.231 & 1.14 & Rússia \\
\hline $\begin{array}{l}\text { Pastas quim. de mad. à soda ou ao sulfato, exceto pastas para } \\
\text { dissolucão. semibranqueadas ou branqueadas, de } n / \text { coníferas }\end{array}$ & 427.134 & 0.98 & China \\
\hline $\begin{array}{l}\text { Outros polietilenos sem carga, densidade }>=0,94 \text { em forma } \\
\text { primária }\end{array}$ & 260.685 & 0.96 & Argentina \\
\hline Polietileno linear, densidade $<0.94$ em forma primária & 209.820 & 0.94 & Bélgica \\
\hline Oleo de soja, em bruto, mesmo degomado & 207.963 & 0.91 & Î́ndia \\
\hline Polietileno sem carga, densidade < 0.94 em forma primária & 207.533 & 0.90 & Argentina \\
\hline $\begin{array}{l}\text { Outras partes e assessórios para tratadores e veículos } \\
\text { automóveis }\end{array}$ & 202 & 0.85 & Argentina \\
\hline $\begin{array}{l}\text { Tabaco não manufaturado, total ou parcialmente destalado, } \\
\text { em folhas secas (light aircured) do tipo Burley }\end{array}$ & 174.164 & 0.81 & EUA \\
\hline $\begin{array}{l}\text { Outros calçados de sola exterior borracha / plastico, de couro } \\
\text { / natural }\end{array}$ & 171.114 & 0.75 & EUA \\
\hline $\begin{array}{l}\text { Outros couros e peles inteiros, de bovinos (incluindo búfalos) } \\
\text { divididos com o lado flor }\end{array}$ & 167.185 & 0.66 & EUA \\
\hline $\begin{array}{l}\text { Carrocerias para veículos automóveis com capacidade de } \\
\text { transporte }=>\text { pessoas, ou para cargas }\end{array}$ & 161.194 & 0.61 & Chile \\
\hline os de propileno, e & 159.248 & 0.59 & Chile \\
\hline Polipropileno sem carga, em forma primária & 151.039 & 0.58 & Argentina \\
\hline Outras espingardas e carabinas de caça ou de tiro & 143.988 & 0.58 & EUA \\
\hline Buta - 1, 3 - dieno não saturado & 132.711 & 0.57 & $\begin{array}{l}\text { Coreia do } \\
\text { Sul }\end{array}$ \\
\hline $\begin{array}{l}\text { Outros calçados cobrindo o tornozelo, parte superior de } \\
\text { borracha / plástico }\end{array}$ & 118.193 & 0.66 & Argentina \\
\hline Preparações alimentícias e conservas, da espécie bovina & 108.641 & 0.61 & $\begin{array}{l}\text { Reino } \\
\text { Unido }\end{array}$ \\
\hline $\begin{array}{l}\text { Consumo de bordo - combustíveis e lubrificantes para } \\
\text { embarcacões }\end{array}$ & 104 & 0.59 & ------ \\
\hline $\begin{array}{l}\text { Partes de outras máquinas e aparelhos para colheita, debulha } \\
\text { etc. }\end{array}$ & 102.920 & 0.58 & Argentina \\
\hline $\begin{array}{l}\text { Outros trigos e misturas de trigo com centeio, exceto para } \\
\text { semeadura }\end{array}$ & 10 & 0.58 & $\begin{array}{l}\text { Correia do } \\
\text { Sul }\end{array}$ \\
\hline Ben & 102.229 & 0.57 & EUA \\
\hline Outr & 5.630 .795 & 31.67 & ------ \\
\hline Total & 17.782 .259 & 100 & -- \\
\hline
\end{tabular}

Fonte: MDIC / Estatística do Comércio Exterior (2019).

O quadro 1 corrobora com a informação disponível no Atlas Socioeconômico (2019) à medida que traz a China como o principal país a receber as exportações do Rio Grande do Sul, assumindo a liderança com o produto da soja. Além disso, é possível identificar a diversificação das atividades econômicas exportadoras do estado.

Segundo Both, Thesing \& Trennepohl (2020), no que tange a região estudada, há uma preponderância de exportações de produtos primários. O incremento de comércio de produtos primários confirma um fenômeno denominado de "reprimarização" da economia brasileira, que é observado no 
conjunto da economia e que se confirma nas regiões de Missões, Noroeste Colonial, Fronteira Noroeste e Celeiro do Rio Grande do Sul.

A partir dos dados apresentados no quadro 1, pode-se relacioná-los com os indicadores socioeconômico do Rio Grande do Sul, com o intuito de compreender o impacto que estes trazem no que diz respeito as exportações do estado. Entre os indicadores escolheu-se o Salário Médio, IDEB, Urbanização de Vias Públicas e População Ocupada. Assim sendo, o tópico seguinte irá descrever brevemente a região noroeste como nosso cenário de pesquisa.

\subsection{A Região Noroeste do Rio Grande do Sul}

A região territorial que abrange o estudo faz parte da região Noroeste do Estado do Rio Grande do Sul, conforme dados da Fundação de Economia e Estatística (FEE, 2017) é representada pela Região Funcional de Planejamento 7, composta por quatro Conselhos Regionais de Desenvolvimento: (1) o COREDE Missões - CM, que compreende uma área de $12.855,5 \mathrm{~km}^{2}$, formada por vinte e cinco municípios, possuindo 251.593 habitantes e 19,1 hab $/ \mathrm{km}^{2}$ de densidade demográfica;(2) COREDE Noroeste Colonial - CNC, que corresponde a uma área de $5.168,0 \mathrm{~km}^{2}$, formada por onze municípios, possuindo 178.918 habitantes e uma densidade demográfica de 32,7 hab $/ \mathrm{km}^{2}$; (3) o COREDE Fronteira Noroeste - CFN, que possui uma população total de 210.564 habitantes em vinte munícipios e uma área de 4.689,0 $\mathrm{km}^{2}$, possui uma densidade demográfica de 43,3 hab $/ \mathrm{km}^{2}$; e ainda, (4) o COREDE Celeiro, que abrange uma população total de 144.442 habitantes em vinte munícipios, e uma área de $4.743,0 \mathrm{~km}^{2}$ com uma densidade demográfica de 29,7 hab $/ \mathrm{km}^{2}$. Nesse estudo optou-se por utilizar os COREDEs Missões e Fronteira Noroeste, como amostra, em virtude de ser os dois maiores COREDES desta mesorregião.

Em termos de representatividade estadual, a região funcional 7, escolhida como território macro da pesquisa, possui cerca de 5,68\% da população do Estado do RS, 8,95\% dos eleitores e a área que abrange o território delimitado representa $8,45 \%$ do território estadual e em termos de produção estimada pelo Produto Interno Bruto (PIB), os quatro COREDEs responderam em 2015 por 5,5\% da produção interna bruta do RS. A figura 1 ilustra o mapa da região funcional de planejamento 7:

Figura 1- Mapa da região funcional de planejamento 7

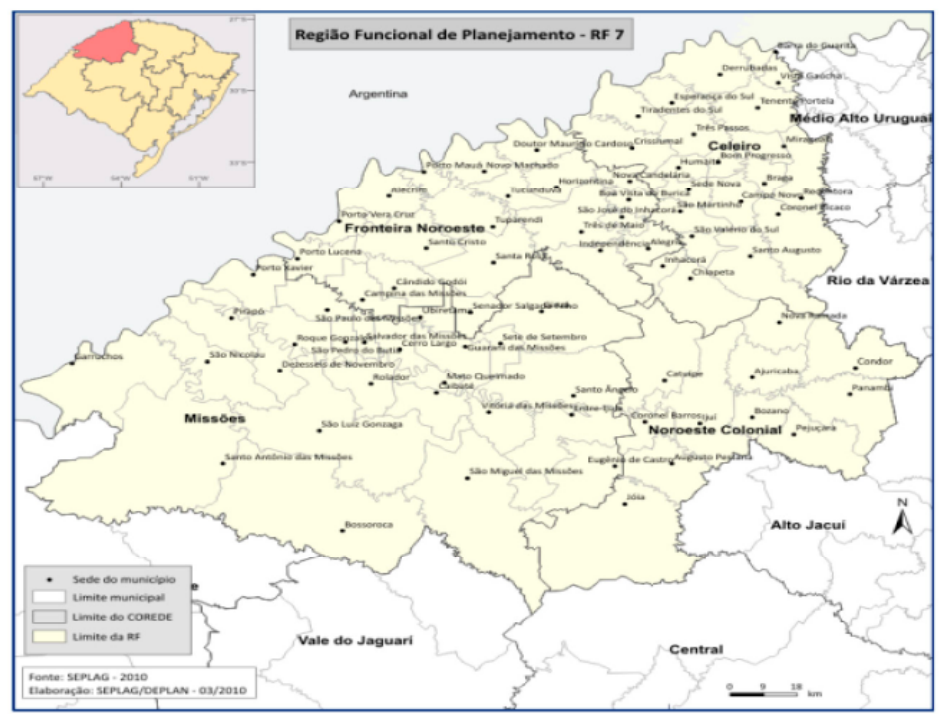

Fonte: SEPLAG (2010). 
Neste contexto, para alcançar o objetivo proposto nesta pesquisa, adotou-se duas hipóteses a serem verificadas, hipótese nula $(\mathrm{H} 0)$ e a hipótese alternativa $(\mathrm{H} 1)$. A hipótese $(\mathrm{H} 1)$ consiste em verificar se: Existe uma relação de influência entre os indicadores socioeconômicos nas exportações de produtos básicos e manufaturados dos municípios da região das missões e fronteira noroeste do estado do Rio Grande do Sul. Sendo assim, a hipótese nula que se roda na regressão, é que (H0) o ajuste do modelo sem previsores é igual ao ajuste do modelo com previsores, ou seja, os indicadores socioeconômicos não explicam as exportações de produtos básicos e manufaturados dos municípios da região das Missões e Fronteira Noroeste do estado do Rio Grande do Sul.

Após as exposições teóricas que abordam o eixo temático do trabalho, a seção seguinte apresenta os procedimentos metodológicos, com destaque para os procedimentos e ferramentas utilizadas no desenvolvimento deste estudo.

\section{PROCEDIMENTOS METODOLÓGICOS}

Para alcançar os objetivos desta pesquisa, foi adotada uma tipologia descrita por Raupp \& Beuren (2003) utilizada em estudos sociais aplicados, na qual considera este estudo como descritivo. Quanto aos fins, portanto, o estudo é caracterizado como descritivo, pois apresenta os principais conceitos além da descrição dos resultados encontrados a partir do output da técnica estatística. Temse, portanto, como variáveis independentes o salário, a população ocupada, a educação dos indivíduos dos 45 municípios e a urbanização de vias públicas e como variável dependente, tem-se as exportações de produtos básicos e manufaturados.

Para Gil (2017), a pesquisa descritiva tem como objetivo a descrição das características de determinada população, tendo como finalidade a identificação de possíveis relações entre as variáveis. Neste sentido, a pesquisa caracteriza-se como descritiva em relação a seu objetivo, aplicada quanto aos procedimentos, por meio do levantamento e a utilização de dados secundário e quantitativa em relação à abordagem do problema. A população desta pesquisa é formada pelos municípios da região territorial que abrange a mesorregião do Noroeste Rio-Grandense, cuja amostra foi delimitada aos municípios pertencentes aos COREDEs Missões e Fronteira Noroeste (figura 1). A pesquisa considerou uma amostra aleatória estratificada, com recorte vertical, fazendo parte deste recorte 45 municípios do estado do Rio Grande do Sul.

Os dados utilizados nesta pesquisa foram coletados junto ao site do Instituto Brasileiro de Geografia e Estatística - IBGE, Fundação de Economia e Estatística - FEE - RS e o site do Ministério da Indústria, Comércio Exterior e Serviços (Balança comercial brasileira - Municípios) para o ano de 2017. Os dados coletados estão publicados em domínio público e foram tabulados e analisados no Software Estatístico LHStat, no qual utilizou-se como tratamento estatístico a análise discriminante.

O objetivo da análise discriminante é transformar as observações multivariadas $\mathbf{x}$ para observações univariadas y tais que os valores de y derivados da população $\pi_{1}$ sejam tão separados quanto possível dos valores de y derivados da população $\pi_{2}$. Fisher (1936) sugeriu tomar os valores y como combinações lineares dos valores $\mathbf{x}$ porque as funções lineares são simples e de fácil manipulação matemática. Estas serão as funções discriminantes procuradas (MARDIA; KENT; BIBBY, 1994). Denotam-se por $\mu_{1 Y}$ e $\mu_{2 Y}$ as médias dos valores de Y obtidos a partir dos valores da multivariada $X$ para as populações $\pi_{1}$ e $\pi_{2}$, respectivamente. Assim procura-se a combinação linear que maximiza a distância entre $\mu_{1 Y}$ e $\mu_{2 Y}$ relativo à variabilidade de Y. Inicia-se por considerar os valores esperados de uma observação multivariada para ambas as populações: 


$$
\boldsymbol{\mu}_{1}=\mathrm{E}\left(\mathbf{X} \mid \pi_{1}\right) ; \quad \boldsymbol{\mu}_{2}=\mathrm{E}\left(\mathbf{X} \mid \pi_{2}\right)
$$

e supor que a matriz de covariância:

$$
\Sigma=\operatorname{Cov}(\mathbf{X})=\mathrm{E}\left[(\mathbf{X}-\boldsymbol{\mu})(\mathbf{X}-\boldsymbol{\mu})^{\prime}\right]
$$

é a mesma para as duas populações. Seja $\ell^{\prime}=\left[\begin{array}{lll}\ell_{1} \ell_{2} & \ldots & \ell_{\mathrm{p}}\end{array}\right]$ um vetor de coeficientes que, com a distribuição multivariada $\mathbf{X}$, determina $\mathrm{Y}$ através da combinação linear:

$$
\mathrm{Y}=\ell^{\prime} \mathbf{X}=\ell_{1} \mathrm{X}_{1}+\ell_{2} \mathrm{X}_{2} \ldots \ell_{\mathrm{p}} \mathrm{X}_{\mathrm{p}}
$$

Portanto Y possui média em cada uma das duas populações; calculadas por:

$$
\begin{aligned}
& \mu_{1 \mathrm{Y}}=\mathrm{E}\left(\mathrm{Y} \mid \pi_{1}\right)=\mathrm{E}\left(\ell^{\prime} \mathbf{X} \mid \pi_{1}\right)=\ell^{\prime} \mu_{1} \\
& \mu_{2 \mathrm{Y}}=\mathrm{E}\left(\mathrm{Y} \mid \pi_{2}\right)=\mathrm{E}\left(\ell^{\prime} \mathbf{X} \mid \pi_{2}\right)=\ell^{\prime} \boldsymbol{\mu}_{2}
\end{aligned}
$$

a depender da população considerada. Já a variância:

$$
\sigma_{Y^{2}}=\mathrm{V}\left(\ell^{\prime} \mathbf{X}\right)=\ell^{\prime} \Sigma \ell
$$

é a mesma para ambas as populações.

A melhor combinação linear é derivada da razão entre o quadrado da distância entre as médias de Y e sua variância:

$$
\frac{\left(\mu_{1 \mathrm{Y}}-\mu_{2 \mathrm{Y}}\right)^{2}}{\sigma_{\mathrm{Y}}^{2}}=\frac{\left(\ell^{\prime} \boldsymbol{\mu}_{1}-\ell^{\prime} \boldsymbol{\mu}_{2}\right)^{2}}{\ell^{\prime} \boldsymbol{\Sigma} \ell}=\frac{\left[\ell^{\prime}\left(\boldsymbol{\mu}_{1}-\boldsymbol{\mu}_{2}\right)\right]^{2}}{\ell^{\prime} \boldsymbol{\Sigma} \ell}=\frac{\left(\ell^{\prime} \boldsymbol{\delta}\right)^{2}}{\ell^{\prime} \boldsymbol{\Sigma} \ell}
$$

onde $\boldsymbol{\delta}=\boldsymbol{\mu}_{1}-\boldsymbol{\mu}_{2}$ é a diferença das médias. Os coeficientes $\ell_{1}, \ell_{2}, \ldots, \ell_{\mathrm{p}}$ de Fisher (1936) são os que maximizam a razão (CHATFIELD; COLLINS, 1980). A função discriminante linear converte as populações multivariadas $\pi_{1}$ e $\pi_{2}$ em populações univariadas tais que as médias univariadas correspondentes são separadas tão bem quanto possível em relação à variância populacional.

Após a descrição dos procedimentos metodológicos utilizado na pesquisa em questão, apresentase no próximo tópico, a apresentação dos resultados obtidos e as análises.

\section{APRESENTAÇÃO DOS RESULTADOS E ANÁLISES}

Em um primeiro momento foi feita a análise discriminante dos municípios que exportam ou não, de forma geral, sem distinção de classe (básico, semi ou manufaturado). Posteriormente a esta análise foi realizada outra análise sobre as exportações em uma classificação quanto a produtos básicos e manufaturados.

Na Tabela 1 são apresentados os dados referentes aos números de municípios (que) e (não) exportam na região das Missões e Fronteira Noroeste. Percebe-se que na coluna dois são expostos o número de munícipios que exportam (GRUPO $1=$ SIM) e os que não exportam (GRUPO 0 = NÃO). Sendo assim, este estudo evidenciou que 26 municípios da região Missões e Fronteira Noroeste não exportam, representando 57,8\% do total. Já outros 19 municípios exportam, perfazendo $42,2 \%$ do total. 
Tabela 1- Número de municípios (que) e (não) exportam na região das Missões e Fronteira Noroeste

\begin{tabular}{l|c|c|c}
\hline Grupo & Casos & \% Casos & Prob. Priori \\
\hline 0=NAO & 26 & $57,8 \%$ & 0,500 \\
1=SIM & 19 & $42,2 \%$ & 0,500 \\
Total & 45 & $100,0 \%$ & \\
\hline
\end{tabular}

Fonte: Dados da pesquisa, 2018.

A tabela 2, apresenta a estatística descritiva (Média e Desvio Padrão) das amostras independentes, sendo elas os salários médios, o IDEB, a urbanização de vias públicas e a população ocupada. A tabela está organizada, por grupo 0 que são os municípios que não exportam e pelo grupo 1 que exporta, logo, tem-se a média e o desvio padrão total.

Tabela 2 - Estatística descritiva das amostras independentes

\begin{tabular}{l|l|c|c}
\hline Grupo & \multicolumn{1}{|c|}{ Preditora } & Média & D. Padrão \\
\hline 0 & Salário Médio & 2,419 & 0,4639 \\
& IDEB & 2,800 & 2,0808 \\
& Urbanização de Vias Públicas & 12,712 & 8,4863 \\
& População Ocupada & 0,676 & 0,6241 \\
\hline 1 & Salário Médio & 2,363 & 0,3670 \\
& IDEB & 3,974 & 1,4992 \\
& Urbanização de Vias Públicas & 18,484 & 14,4237 \\
& População Ocupação & 4,592 & 7,0034 \\
\hline Total & Salário Médio & 2,396 & 0,4221 \\
& IDEB & 3,296 & 1,9295 \\
& Urbanização de Vias Públicas & 15,149 & 11,5906 \\
& População Ocupada & 2,329 & 4,9105 \\
\hline
\end{tabular}

Fonte: Dados da pesquisa, 2018.

Na estatística descritiva, foi possível observar que as médias e os desvios padrão maiores estão no grupo 1, sendo estes, os municípios que exportam. Em uma escala de 1 a 5, o total atesta que o salário médio, o IDEB e a população ocupada foi de 2,396, 3,296 e 2,329 respectivamente. Já em uma escala de 0 a 100, a média da urbanização ficou na casa dos 15,149, sendo um valor baixo, podendo afirmar que os munícipios, no âmbito geral, possuem pouca urbanização de vias públicas (baixa mobilidade urbana). Quanto ao desvio padrão, tem o objetivo de evidenciar o quanto os valores dos quais se extraiu a média são próximos ou distantes da própria média. Neste caso, o desvio padrão total do salário médio, do IDEB, da urbanização de vias públicas e a população ocupada foram, respectivamente de: 0,4221, $1,9295,11,5906$ e 4,9105 .

Na tabela 3, observa-se a matriz de covariância total, na qual é uma matriz quadrada que contém as variâncias e covariâncias associadas a diversas variáveis. Neste caso, os elementos na diagonal da matriz são representados pelos desvios das variáveis, e os elementos fora da diagonal são as covariâncias entre todos os possíveis pares de variáveis (FÁVERO; BELFIORE, 2015). 
Tabela 3 - Matriz de Covariância Total

\begin{tabular}{l|c|c|c|c}
\multicolumn{1}{c|}{ Variável } & SalárMed & IDEB & Urban & $\begin{array}{c}\text { Popul. } \\
\text { Ocup. }\end{array}$ \\
\hline SALAR MED. & 0,1782 & $-0,3209$ & $-0,4746$ & $-0,0263$ \\
IDEB & $-0,3209$ & 3,7232 & 0,2093 & 2,3942 \\
URBAN. & $-0,4746$ & 0,2093 & 134,3416 & 5,6010 \\
POPUL. OCUP. & $-0,0263$ & 2,3942 & 5,6010 & 24,1131 \\
\hline
\end{tabular}

Fonte: Dados da pesquisa, 2018.

Quanto aos testes de normalidade, das amostras independentes, foi feito o teste de Sh: Wilk, no qual se constatou que a Hipótese H0: a distribuição da variável é normal, conforme a tak

Tabela 4 - Teste de Shapiro-Wilk

\begin{tabular}{l|c|c}
\hline Variável & Estatística & Valor $\boldsymbol{p}$ \\
\hline SALAR MED. & 0,7977 & 0,0000 \\
IDEB & 0,8216 & 0,0000 \\
URBAN. & 0,8963 & 0,0007 \\
POPUL. OCUP. & 0,4393 & 0,0000 \\
\hline
\end{tabular}

Fonte: Dados da pesquisa, 2018.

Diante do teste de Shapiro-Wilk, partiu-se para o teste de Mardia, com análise multivariada de assimetria e curtose. Sendo que a Hipótese H0: a distribuição conjunta das variáveis é normal multivariada, conforme tabela 5:

Tabela 5 - Teste de Mardia

\begin{tabular}{l|c|c|c}
\hline Medida & Coeficiente & Estatística & Valor $\boldsymbol{p}$ \\
\hline Assimetria & 22,0538 & 165,4038 & 0,0000 \\
Curtose & 41,0763 & 8,2670 & 0,0000 \\
\hline
\end{tabular}

Fonte: Dados da pesquisa, 2018.

Neste caso, H0 deveria ser rejeitada se ao menos um dos valores-p fossem inferior ao nível de significância. Realizou-se ainda o teste de homogeneidade das covariâncias dos grupos, na qual apresentou os seguintes resultados:

$\mathrm{M}$ de $\mathrm{Box}=102,1417$

$\mathrm{F}$ aprox. $=9,1412$

Graus de liberdade: $\mathrm{n} 1=10 ; \mathrm{n} 2=7068,55$

Hipótese nula: as matrizes de covariância dos grupos são iguais

Valor-p (sign.) $=0,0000$

Quanto aos valores próprios, tem-se na tabela 6, o autovalor, \% de variação, \% acumulado e o valor da correlação canônica:

Tabela 6 - Valores próprios

\begin{tabular}{c|c|c|c|c}
\hline Funcão & Autovalor & \% variacão & \% acumul. & Corr.canônica \\
\hline 1 & 0,335 & 100,0 & 100,0 & 0,501 \\
\hline
\end{tabular}

Fonte: Dados da pesquisa, 2018. 
Perante a isso, tem-se os coeficientes de função discriminante canônica, na qual pode ser observado:

Tabela 7 - Função discriminante canônica

\begin{tabular}{l|c|c}
\hline & Função $^{\text {n }} \mathbf{1}$ & Função $^{\text {p }} \mathbf{1}$ \\
\hline SALAR MED. & 0,2975 & 0,1267 \\
IDEB & 0,2879 & 0,5354 \\
URBAN. & 0,0434 & 0,4931 \\
POPUL. OCUP. & 0,1466 & 0,6679 \\
\hline (Constante) & $-2,6607$ & \\
\hline
\end{tabular}

$n=$ coeficientes não padronizados; $p=$ coeficientes padronizados

Fonte: Dados da pesquisa, 2018.

Diante da tabela 7, pode-se inferir que perante os coeficientes não padronizados e padronizados, quais indicadores possuem maior influência de o município SER ou NÃO exportador. Analisando os resultados do coeficiente padronizado, pode-se inferir, portanto, que diante dos 4 indicadores analisados, o que possui maior impacto é a população ocupada (0,6679). Sendo assim, quanto maior o município em nível de população, o número de pessoas ocupadas tende a ser maior, com isso as chances de o município ser exportador consequentemente é maior. O trabalho seminal de Thomas (1964) sucinta isso, que se o tamanho da população é constante ou se está em declínio, então o crescimento econômico e das exportações depende, principalmente, do efeito da produtividade e o aumento da taxa de inovação, e este último, possui um intenso efeito nos fluxos comerciais de um país para com o outro (VIEIRA FILHO; FISHLOW, 2017; BRAGA; MELO, 2017).

O segundo indicador com maior influência nas exportações é o IDEB com $(0,5354)$. O Índice de Desenvolvimento da Educação Básica - IDEB é importante quando se trata da capacidade intelectual e dos reflexos que isso gera nos municípios com bons resultados. Pode-se inferir que o IDEB influência positivamente nas potencialidades do município ser exportador, quando obtém bons índices de IDEB. Assim, uma população bem instruída é de primordial importância na promoção do crescimento econômico (THOMAS, 1964).

O terceiro indicador que diz muito sobre o município ser ou não exportador, que é a urbanização de vias públicas $(0,4931)$. Este indicador refere-se basicamente a mobilidade urbana dos municípios, ou seja, municípios que possuem uma boa mobilidade, são mais propensos a serem exportador. Alguns dos problemas da falta de mobilidade nos munícipios incluem o ritmo acelerado de motorização, condições de demanda local que excedem em muito a capacidade das instalações e a incompatibilidade da estrutura urbana com o aumento da motorização (GAKENHEIMER, 1999).

O último indicador diz respeito ao salário médio $(0,1267)$. Nesta análise, levando em consideração a exportação de forma geral, o salário médio não foi de grande relevância, para assim poder inferir que quanto maior o salário médio mais propenso é o município de ser exportador. Estudos já relatam que a exportação é capaz de exercer um efeito multiplicador, aumentando os níveis de renda e de emprego da população, além de ser elemento-chave sobre as condições de desenvolvimento de determinadas economias nacionais (MUNDURUCA; SANTANA, 2012; FARIAS; FARIAS, 2018). Sendo, assim, as exportações, torna-se um indutor do crescimento econômico do país ou região, especialmente em economias pequenas. Perante a isso, a tabela 8 esboça a estatísticas dos casos, na qual a partir desta estatística, se analisa cada município, se ele está classificado de uma forma correta, e se ele pode ter características de exportador (observado), mas está (previsto) que não, e vice-versa.

\section{3}


Tabela 8 - Estatísticas dos casos

\begin{tabular}{|c|c|c|c|}
\hline & & & PROB. GROPO \\
\hline MUNICÍPIOS & Observado & Previsto & Previsto \\
\hline Bossoroca & 1 & $0^{\mathrm{a}}$ & 0,629 \\
\hline Caibaté & 0 & 0 & 0,550 \\
\hline Cerro Largo & 1 & 1 & 0,671 \\
\hline Dezesseis de Novembro & 0 & 0 & 0,754 \\
\hline Entre-Ijuís & 0 & 0 & 0,534 \\
\hline Eugênio de Castro & 0 & 0 & 0,728 \\
\hline Garruchos & 0 & 0 & 0,792 \\
\hline Giruá & 0 & $1^{\mathrm{a}}$ & 0,539 \\
\hline Guarani das Missões & 1 & 1 & 0,509 \\
\hline Mato Queimado & 0 & 0 & 0,799 \\
\hline Pirapó & 0 & 0 & 0,814 \\
\hline Porto Xavier & 1 & $0^{\mathrm{a}}$ & 0,662 \\
\hline Rolador & 0 & 0 & 0,748 \\
\hline Roque Gonzales & 0 & 0 & 0,510 \\
\hline Salvador das Missões & 1 & $0^{\mathrm{a}}$ & 0,615 \\
\hline Santo Ângelo & 1 & 1 & 0,962 \\
\hline Santo Antônio das Missões & 0 & 0 & 0,728 \\
\hline São Luiz Gonzaga & 1 & 1 & 0,600 \\
\hline São Miguel das Missões & 1 & $0^{\mathrm{a}}$ & 0,582 \\
\hline São Nicolau & 0 & 0 & 0,891 \\
\hline São Paulo das Missões & 0 & $1^{\mathrm{a}}$ & 0,543 \\
\hline São Pedro do Butiá & 0 & $1^{\mathrm{a}}$ & 0,551 \\
\hline Sete de Setembro & 0 & 0 & 0,671 \\
\hline Ubiretama & 0 & 0 & 0,778 \\
\hline Vitória das Missões & 0 & 0 & 0,719 \\
\hline Alecrim & 0 & 0 & 0,616 \\
\hline Alegria & 0 & 0 & 0,584 \\
\hline Boa Vista do Buricá & 1 & 1 & 0,788 \\
\hline Campina das Missões & 0 & $1^{\mathrm{a}}$ & 0,710 \\
\hline Cândido Godói & 1 & 1 & 0,838 \\
\hline Doutor Maurício Cardoso & 0 & $1^{\mathrm{a}}$ & 0,639 \\
\hline Horizontina & 1 & 1 & 0,850 \\
\hline Independência & 1 & 1 & 0,523 \\
\hline Nova Candelária & 1 & 1 & 0,712 \\
\hline Novo Machado & 1 & $0^{\mathrm{a}}$ & 0,741 \\
\hline Porto Lucena & 0 & 0 & 0,819 \\
\hline Porto Mauá & 1 & $0^{\mathrm{a}}$ & 0,815 \\
\hline Porto Vera Cruz & 0 & 0 & 0,856 \\
\hline Santa Rosa & 1 & 1 & 0,990 \\
\hline Santo Cristo & 1 & 1 & 0,809 \\
\hline São José do Inhacorá & 0 & 0 & 0,515 \\
\hline Senador Salgado Filho & 0 & 0 & 0,796 \\
\hline Três de Maio & 1 & 1 & 0,792 \\
\hline Tucunduva & 0 & $1^{\mathrm{a}}$ & 0,554 \\
\hline Tuparendi & 1 & $0^{\mathrm{a}}$ & 0,615 \\
\hline
\end{tabular}

a é caso de classificação errônea. Erros = 13 (28,9\%).

Fonte: Dados da pesquisa, 2018. 
Neste contexto, observa-se que os municípios de Bossoroca, Porto Xavier, Salvador das Missões, São Miguel das Missões, Novo Machado, Porto Mauá e Tuparendi são observados e classificados como exportadores, mas possuem característica (previsto) perante os dados levantados, como municípios não exportadores. $\mathrm{O}$ percentual de probabilidade dos respectivos municípios quanto a este previsto foi de: $62 \%$, 66\%, 61\%, 58\%, 74\%, 81\% e 61\%. Quanto aos municípios de Giruá, São Paulo das Missões, São Pedro do Butiá, Campina das Missões, Doutor Maurício Cardoso e Tucunduva estão classificados como não exportadores. Segundo a classificação prevista, são munícipios com um potencial exportador, tendo um percentual probabilístico de acerto nesta previsão de 54\%, 54\%, 55\%, 71\%, 63\% e 55\% respectivamente.

Os demais municípios foram classificados de forma que o resultado do observado foi a mesma do previsto, ou seja, observado como não exportador e previsto como não exportador, e vice-versa. Com relação a matriz de confusão, a tabela 9 demostra os seguintes resultados:

Tabela 9- Matriz de confusão

\begin{tabular}{c|c|c|c|c}
\hline \multicolumn{5}{c}{ CLASSIF. COMO } \\
\hline Grupo & Casos & $\mathbf{0}$ & $\mathbf{1}$ & Acerto \\
\hline 0 & 26 & 20 & 6 & $76,9 \%$ \\
1 & 19 & 7 & 12 & $63,2 \%$ \\
Total & $\mathbf{4 5}$ & $\mathbf{2 7}$ & $\mathbf{1 8}$ & $\mathbf{7 1 , 1 \%}$ \\
\hline
\end{tabular}

Fonte: Dados da pesquisa, 2018.

Diante da matriz, pode-se observar que dos 26 casos (municípios) classificados como não exportadores, 20 condizem com a classificação de não exportadores e 6 com características exportadoras mesmo não exportando. Já os outros 19 municípios classificados no grupo dos exportadores, 7 deles não possuem características exportadoras mesmo sendo exportadores, enquanto os outros 12 permanece com tal classificação. Os acertos para tais afirmações são de $76,9 \%$ no grupo 0 (municípios não exportadores) e de 63,2\% no grupo 1 (municípios exportadores), com uma média total de acertos de $71,1 \%$. Diante dos dados apresentados até então, sobre a influência de determinados indicadores nas exportações de 45 municípios, parte-se para uma análise mais específica.

O objetivo, portanto, é analisar a influência destes mesmos indicadores sobre os municípios (que) e (não) exportam produtos básicos e manufaturados, verificando se os indicadores irão apresentar resultados diferentes. Sendo assim, se inicia pela análise de produtos básicos. Considerando que os devidos dados passaram pelos mesmos testes de normalidade (Shapiro-Wilk, de Mardia e de homogeneidade das covariâncias dos grupos). A distribuição conjunta das variáveis é normal multivariada. Portanto, a tabela 10 trata do número de municípios (que) e (não) exportam produtos básicos na região das Missões e Fronteira Noroeste.

Tabela 10 - Municípios (que) e (não) exportam produtos básicos na região das Missões e Fronteira Noroeste.

\begin{tabular}{l|c|c|c}
\hline Grupo & Casos & \% Casos & Prob. priori \\
\hline 0=NAO & 35 & $77,8 \%$ & 0,500 \\
$1=$ SIM & 10 & $22,2 \%$ & 0,500 \\
Total & 45 & $100,0 \%$ & \\
\hline
\end{tabular}

Fonte: Dados da pesquisa, 2018. 
Este estudo evidenciou que o número de municípios que não exportam (35) é maior que os que exportam (10) produtos básicos. Diante disso, parte-se direto para a matriz de confusão, na qual irá classificar e mensurar o percentual de acertos. Veja na tabela 11:

Tabela 11 - Matriz de confusão

\begin{tabular}{c|c|c|c|c}
\hline \multicolumn{5}{c}{ OBSERVADO } \\
\hline Grupo & Casos & $\mathbf{0}$ & $\mathbf{1}$ & Acerto \\
\hline 0 & 35 & 34 & 1 & $97,1 \%$ \\
1 & 10 & 6 & 4 & $40,0 \%$ \\
Total & $\mathbf{4 5}$ & $\mathbf{4 0}$ & $\mathbf{5}$ & $\mathbf{8 4 , 4 \%}$ \\
\hline
\end{tabular}

Fonte: Dados da pesquisa, 2018.

Pode-se observar que dos 35 casos (municípios) classificados como não exportadores, 34 condizem com a classificação de não exportadores e 1 com características exportadoras mesmo não exportando. Já os outros 10 municípios classificados no grupo dos exportadores, 6 deles não possuem características exportadoras mesmo sendo exportador, enquanto os outros 4 permanece com tal classificação. Os acertos para tais afirmações são de 97,1\% no grupo 0 (municípios não exportadores) e de $40 \%$ no grupo 1 (municípios exportadores), com uma média total de acertos de 84,4\%. Estes resultados podem ser observados quando analisamos a tabela 11. Perante a isso, tem-se os coeficientes de função discriminante canônica, na qual pode ser observado na tabela 12:

Tabela 12 - Função discriminante canônica

\begin{tabular}{l|c|c}
\hline & Função $^{\text {"1 }}$ & Funçã̃o $^{\text {p }} \mathbf{1}$ \\
\hline SALAR MED. & 0,7909 & 0,3329 \\
IDEB & $-0,1963$ & $-0,3808$ \\
URBAN. & $-0,0607$ & $-0,6965$ \\
POPUL. OCUP. & 0,1295 & 0,6366 \\
\hline
\end{tabular}

$n=$ coeficientes não padronizados; $p=$ coeficientes padronizados

Fonte: Dados da pesquisa, 2018.

Analisando os resultados do coeficiente padronizado, pode-se inferir que diante dos 4 indicadores, o que possui maior impacto novamente é a população ocupada $(0,6366)$. O segundo indicador com impacto positivo, é o salário médio $(0,3329)$, estando em duas posições acima, quando analisado com as exportações de forma geral. Já os demais indicadores IDEB (-,6965) e urbanização de vias públicas $(-0,3329)$ possui um impacto negativo. Neste sentido, pode-se inferir que estes últimos dois indicadores não influenciam em o município ser exportador de produtos básicos, sendo um caso a ser estudado mais a fundo estas causas. Perante a isso, parte-se para a última análise, na qual trata dos municípios (que) e (não) exportam produtos manufaturados. Veja na tabela 13 a classificação. 
Tabela 13- Municípios (que) e (não) exportam produtos manufaturados na região das Missões e Fronteira Noroeste.

\begin{tabular}{l|c|c|c}
\hline Grupo & Casos & \% Casos & Prob. priori \\
\hline 0=NAO & 34 & $75,6 \%$ & 0,500 \\
$1=$ SIM & 11 & $24,4 \%$ & 0,500 \\
Total & 45 & $100,0 \%$ & \\
\hline
\end{tabular}

Fonte: Dados da pesquisa, 2018.

Este estudo evidenciou que o número de municípios que não exportam (34) é maior que os que exportam (11) produtos manufaturados. Sendo assim, parte-se direto para a matriz de confusão, na qual irá classificar e mensurar o percentual de acertos. Veja na tabela 14:

Tabela 14 - Matriz de confusão

\begin{tabular}{|c|c|c|c|c|}
\hline \multicolumn{2}{|c|}{ OBSERVADO } & \multicolumn{2}{|c|}{ CLASSIF. COMO } & \multirow[b]{2}{*}{ Acerto } \\
\hline Grupo & Casos & $\mathbf{0}$ & 1 & \\
\hline 0 & 34 & 24 & 10 & $70,6 \%$ \\
\hline 1 & 11 & 4 & 7 & $63,6 \%$ \\
\hline Total & 45 & 28 & 17 & $68,9 \%$ \\
\hline
\end{tabular}

Fonte: Dados da pesquisa, 2018.

Pode-se observar que dos 34 casos (municípios) classificados como não exportadores, 24 condizem com a classificação de não exportadores e 10 com características exportadoras mesmo não exportando. Já os outros 11 municípios classificados no grupo dos exportadores, 4 deles não possuem características exportadoras mesmo sendo exportador, enquanto os outros 7 permanecem com tal classificação. Os acertos para tais afirmações foram inferiores tanto na exportação geral quanto de produtos básicos, tendo acertos de 70,6\% no grupo 0 (municípios não exportadores) e de $63,6 \%$ no grupo 1 (municípios exportadores), com uma média total de acertos de 68,9\%. Neste caso, estes resultados não foram diferentes da tabela 11. Sendo assim, tem-se, portanto, os coeficientes de função discriminante canônica, na qual pode ser observado na tabela 15:

Tabela 15 - Função discriminante canônica

\begin{tabular}{l|c|c}
\hline & Função $^{\mathbf{n}} \mathbf{1}$ & Função $^{\mathbf{p}} \mathbf{1}$ \\
\hline SALAR MED. & 0,7909 & 0,3329 \\
IDEB & $-0,1963$ & $-0,3808$ \\
URBAN. & $-0,0607$ & $-0,6965$ \\
POPUL. OCUP. & 0,1295 & 0,6366 \\
\hline (Constante) & $-0,6292$ \\
\hline
\end{tabular}

$\mathrm{n}=$ coeficientes não padronizados; $\mathrm{p}=$ coeficientes padronizados

Fonte: Dados da pesquisa, 2018.

Com os resultados do coeficiente padronizado, pode-se por fim, inferir que diante dos 4 indicadores, o que possui maior impacto, como nos demais é a população ocupada $(0,6366)$. O segundo indicador com impacto positivo é o salário médio (0,3329), estando em duas posições acima, quando analisado 
com as exportações de forma geral. Já os demais indicadores IDEB (-0,6965) e urbanização de vias públicas $(-0,3329)$ possui um impacto negativo. Neste caso, precisa ser estudado, pois com estes dados se demostrou que IDEB e urbanização de vias públicas, quanto maior estes índices vão na contramão de caracterizar um município como ser exportador. Como se observa, os resultados das exportações básicos e manufaturados são praticamente iguais, com uma variação insignificante no número de casos (0 e 1$)$.

Diante da apresentação e discussões dos resultados obtidos a partir da análise, parte-se para as considerações finais deste estudo.

\section{CONSIDERAÇÕES FINAIS}

Diante deste breve estudo, o qual teve como objetivo verificar a influência dos indicadores socioeconômicos nas exportações de produtos básicos e manufaturados dos municípios da região das Missões e Fronteira Noroeste do estado do Rio Grande do Sul. Evidenciou-se que o indicador que possui maior influência nas exportações de modo geral é a população ocupada com 0,6679, logo, tem-se o IDEB com 0,5354, a urbanização de vias públicas com 0,4931 e salário médio 0,1267. A escala nesta análise vai de 0 a 1, sendo que, quanto mais próximo de um maior é a influência. Quando analisado por distinção de classe (produto básico e manufaturado) os resultados foram os mesmos em ambos, mas diferente das exportações de modo geral. A população ocupada tanto na classe de produtos básicos quanto manufaturados possui 0,6366, o salário médio é de 0,3329 e os demais indicadores IDEB com -0,6965 e urbanização de vias públicas -0,3329 com impacto negativo.

Perante a significância do modelo, é possível aceitar a hipótese H1, inferindo que existe uma relação de influência entre os indicadores socioeconômicos nas exportações de produtos básicos e manufaturados dos municípios da região das Missões e Fronteira Noroeste do estado do Rio Grande do Sul, com algumas particularidades. Sendo assim, observou-se também a partir da técnica estatística que alguns municípios foram observados e classificados como exportadores, mas possuem características (previsto) perante os dados levantados, como não exportadores, sendo 7 municípios. Já outros 6 municípios estão classificados como não exportadores e os demais 32, foram classificados de forma que o resultado do observado foi a mesma do previsto, ou seja, observado como não exportadores e previsto como não exportadores, e vice-versa.

Como limitação deste estudo, tem-se que, para fins de análise, foi considerada uma relação unidirecional entre indicadores socioeconômico e exportação. Sugere-se, para pesquisas futuras, que seja investigada a relação multilateral destes indicadores para se obter uma análise mais sofisticada e completa sobre a dinâmica de interação dos construtos. Além disso, o uso de dados secundários para indicadores socioeconômicos e de exportação pode ser considerado como uma limitação, poisa análise fica condicionada aos métodos utilizados pelas organizações que fornecem os indicadores.

Como este estudo não visava esgotar todas as possibilidades de análise, novas pesquisas são sugeridas para identificar principalmente de forma qualitativa, o quão cada indicador analisado, impacta nas exportações. Sugere-se que sejam feitas novas análises por setor de atividade nestes devidos municípios, bem como o estudo em outras regiões do estado para assim se fazer comparativos. Desta forma, conclui-se que a literatura de desenvolvimento regional do ponto de vista dos indicadores socioeconômicos e a teoria da base exportadora ainda não está totalmente consolidada. Desse modo, há pleno espaço para o desenvolvimento de novos estudos que testem e expliquem outras relações entre estes temas. 


\section{REFERÊNCIAS}

BOTH, B.; THESING, N. J.; TRENNEPOHL, D. cadeia global de valor: um estudo da inserção via comércio internacional, dos municípios dos Coredes Missões, Noroeste Colonial, Fronteira Noroeste e Celeiro do Rio Grande Do Sul. Qualitas Revista Eletrônica, Campina Grande, PB, v. 20, n. 1, p. 111-127, 2020.

BRAGA, F. L. P.; DE MELO, M. C. P. Intensidade tecnológica das transações externas brasileiras (2005-2015): uma análise regional. Revista Brasileira de Estudos Regionais e Urbanos, Curitiba, PR, v. 11, n. 3, p. 314-335, 2017.

CABUGUEIRA, A. C. C. M. Do desenvolvimento regional ao desenvolvimento local: análise de alguns aspectos de política econômica regional. Gestão e Desenvolvimento, Lisboa, n. 9, p. 103136, 2000.

CHATFIELD, C.; COLLINS, A.J. Introduction to Multivariate Analysis. London: Chapman and Hall, 1980.

DALLABRIDA, V. R. et al. Estratégias de gestão do processo de desenvolvimento: diagnóstico e análise sobre a Região Fronteira Noroeste-RS. In: DALLABRIDA, V. R.; BÜTTENBENDER, P. L. (orgs.). Gestão, inovação e desenvolvimento: oportunidades e desafios para o desenvolvimento da região fronteira noroeste. Santa Cruz: Edunisc,2007.

EVANGELISTA, M. L.; RAMBO, J. A. Cenários e perspectivas para arranjos produtivos locais do agronegócio da região fronteira noroeste do Rio Grande do Sul. In: DALLABRIDA, V. R.;

BÜTTENBENDER, P. L. (orgs.). Gestão, inovação e desenvolvimento: oportunidades e desafios para o desenvolvimento da região fronteira noroeste. Santa Cruz: Edunisc, 2017.

FARIAS, A. C. da S.; FARIAS, R. B. A. Desempenho comparativo entre países exportadores de pescado no comércio internacional: Brasil eficiente?. Revista de Economia e Sociologia Rural, Brasília, DF, v. 56, n. 3, p. 451-466, 2018.

FÁVERO, L.P.; BELFIORE, P. Análise de dados: técnicas multivariadas exploratórias com SPSS e STATA. São Paulo: Atlas, 2015.

FERREIRA, F. D. da S.; MEDEIROS, E. H. O. de. Teoria da base de exportação: uma avaliação da base de exportação da região sul do brasil. Revista Eletrônica de Economia da Universidade Estadual de Goiás, Anápolis, GO, v.12, n.02, p.237-251, jul./dez.2016.

FISCHER, T. Poderes locais, desenvolvimento e gestão. São Paulo: ABDL, 2004.

FISHER, R. A. The use of multiple measurements in taxonomic problems. Annals of Eugenics, v. 7, n.2, p. 179-188, 1936. 
FOCHEZATTO, A. Desenvolvimento regional: novas abordagens para novos paradigmas produtivos. O Ambiente Regional: Três Décadas de Economia Gaúcha, Rio Grande do Sul, v.1, p. 160-192, 2010.

FRANZIN, S. F. L.; DE ALMEIDA, F. M.; DE SOUZA, C. H. M. A inovação e o desenvolvimento regional como referência para políticas públicas no brasil. Inter Science Place, Campos dos Goytacazes, RJ, v.1, n.29, 2015.

FUNDAÇÃO DE ECONOMIA E ESTATÍSTICA (FEE). Governo do Estado do Rio Grande do Sul. 2017. Disponível em: https://www.fee.rs.gov.br/. Acesso em: 04 ago.2020.

GAKENHEIMER, R. Urban mobility in the developing world. Transportation Research Part A: Policy and Practice, v. 33, n. 7-8, p. 671-689, 1999.

GIL, A. C. Como elaborar projetos de pesquisa. 6.ed. São Paulo: Atlas, 2017.

LIMA, E. C. de L. et al. Teoria da base de exportação e sua relação com o desempenho econômico: o caso do estado de Santa Catarina. Revista Textos de Economia, Florianópolis, SC, v. 16, n. 1, 2013.

LOBO, A. S. Teoria da base de exportação e a dinâmica socioeconômica do Matopiba: uma análise espacial. Dissertação (Mestrado em Políticas Públicas e Desenvolvimento) - Instituto de Pesquisa Econômica Aplicada, IPEA, 2019.

MARDIA, K.V.; KENT, J.T.; BIBBY, J.M. Multivariate analysis. 2.ed. London: Academic, 1994.

MUNDURUCA, D. F. V.; SANTANA, J. R. comércio exterior como estratégia de crescimento econômico: uma proposta de priorização de produtos exportáveis para a economia sergipana.

Documentos Técnicos Científicos, v.43, jul./set.2012.

NORTH, D. Teoria da localização e crescimento econômico regional. In: SCHWARTZMANN, J. (org.). Economia regional e urbana: textos escolhidos. Belo Horizonte: UFMG, 1977.

OLIVEIRA, P. R. da S.; FERASSO, M. A Exportação como caminho para o desenvolvimento local: o caso da região metropolitana de Campinas. REGMPE, Brasil-BR, v.3, n.3, p. 1-22, set./dez.2018.

OLIVEIRA, N. M. de; NÓBREGA, A. M.; MEDEIROS, M. R. Desenvolvimento Econômico e Regional segundo a teoria da base de exportação. Revista Tocantinense de Geografia, Araguaína, TO, v. 1, n. 01, 2013.

RAUPP, F. M.; BEUREN, I. M. Metodologia da pesquisa aplicável às ciências sociais. In: BEUREN, I. M. (org.). Como elaborar trabalhos monográficos em contabilidade: teoria e prática. São Paulo: Atlas, 2003. 
RICHARDSON, R. J. et al. Pesquisa social: métodos e técnicas. 3.ed. São Paulo: Atlas, 2014. SACHS, W. Dicionário do desenvolvimento: guia para o conhecimento como poder. Petrópolis: Vozes, 2000.

SAMPIERI, R. H.; COLLADO, C. F.; LUCIO, P. B. Metodologia de pesquisa. 5.ed. São Paulo: Penso, 2013.

SECRETÁRIA DE PLANEJAMENTO, GOVERNANÇA E GESTÃO (SEPLAG), 2010.

Disponível em: http://planejamento.rs.gov.br/inicial Acesso em: 04 ago.2020.

SILVEIRA, D. C. da; FEISTEL, P. R.; BRUM, A. L. As exportações da região sul do Brasil: uma análise do setor agropecuário. Redes (St. Cruz Sul, Online), v. 24, n. 3, p. 272-294, 2019.

SIRKIN, G. The theory of the regional economic base. The Review of Economics and Statistics, v. 41, n. 4, p. 426-429, nov.1959.

SOTO, W. E. G. A. Dialética do desenvolvimento regional: capital social, democracia, redes empresariais e dinâmicas territoriais. In: BECKER, D. F.; WITTMANN, M. L. (orgs.).

Desenvolvimento regional: abordagens interdisciplinares. Santa Cruz do Sul, SC: Edunisc, 2003.

SOUZA, N. J. Desenvolvimento econômico. São Paulo: Atlas, 1999.

SOUZA, N. J. Exportações e crescimento econômico do RS - 1951-2011. Revista Ensaios FEE. Porto Alegre, RS, v. 23, 2002. Edição Especial.

SPGG. Atlas Socioeconômico. 2019.Disponível em: <http://www.atlassocioeconomico.rs.gov.br/ participacao-nas-exportacoes-e-produtos>. Acesso em: 18 ago. 2020.

THOMAS, M. D. The export base and development stages theories of regional economic growth: An appraisal. Land Economics, v. 40, n. 4, p. 421-432, 1964.

TIEBOUT, C. A Pure Theory of Local Expenditures. Journal of Political Economy, v. 64, p. 416424, 1956.

VIEIRA FILHO, J. E. R.; FISHLOW, A. Agricultura e indústria no Brasil: inovação e competitividade. Brasília: Ipea, 2017. 305 p. Disponível em: file://C:/Users/ronal/Downloads/ Agricultura\%20e\%20ind\%C3\%BAstria\%20no\%20Brasil_inova\%C3\%A7\%C3\%A3o\%20e\%20 competitividade.pdf. Acesso em: 18 ago. 2020.

ZUCATTO, L; FERASSO, M; EVANGELISTA, M. A importância das exportações para o desenvolvimento local da fronteira Noroeste do Rio Grande do Sul e do Extremo-Oeste de Santa Catarina. Revista de Gestão dos Países de Língua Portuguesa, Rio de Janeiro, v. 9, n. 1-2, p. 97 $111,2010$. 


\section{Dados dos autores:}

\section{Ronaldo Leão de Miranda}

ORCID: https://orcid.org/0000-0001-6778-2463

Mestre em Desenvolvimento Regional. Doutorando em Ciências Contábeis e Administração pela Universidade Regional de Blumenau (FURB). Blumenau / SC - Brasil. E-mail: ronaldo_leaomiranda@ hotmail.com

\section{Glaucius André França}

ORCID: https://orcid.org/0000-0001-9202-8593

Mestre em Ciências Contábeis e Atuariais. Professor da Universidade Estadual do Paraná, (UNESPAR) e Doutorando em Ciências Contábeis e Administração pela Universidade Regional de Blumenau (FURB). Blumenau / SC - Brasil. E-mail: glaucius.franca@ outlook.com

\section{Nelson Hein}

ORCID: https://orcid.org/0000-0002-8350-9480

Doutor em Engenharia de Produção. Professor do Programa de Pós-Graduação em Ciências Contábeis e Administração da Universidade Regional de Blumenau (FURB). Blumenau / SC - Brasil. E-mail: hein@furb.br 